\title{
Functional compatibility between Purkinje cell axon branches and their target neurons in the cerebellum
}

\author{
Zhilai Yang ${ }^{1,5, *}$, Na Chen ${ }^{1, *}$, Rongjing Ge ${ }^{4, *}$, Hao Qian ${ }^{1}$ and Jin-Hui Wang ${ }^{1,2,3,4}$ \\ ${ }^{1}$ Institute of Biophysics, Chinese Academy of Sciences, Beijing 100101, China \\ ${ }^{2}$ College of Life Science, University of Chinese Academy of Sciences, Beijing 100049, China \\ ${ }^{3}$ Qingdao University, School of Pharmacy, Shandong 266021, China \\ ${ }^{4}$ Department of Physiology, Bengbu Medical College, Bengbu 233000, China \\ ${ }^{5}$ Department of Anesthesiology, The First Affiliated Hospital of Anhui Medical University, Hefei 230022, China \\ *These authors have contributed equally to this work
}

Correspondence to: Jin-Hui Wang, email: jhw@sun5.ibp.ac.cn

Keywords: axon, neuron, action potential, synaptic transmission, Purkinje cell

Received: May 30, $2017 \quad$ Accepted: June 28, $2017 \quad$ Published: August 01, 2017

Copyright: Yang et al. This is an open-access article distributed under the terms of the Creative Commons Attribution License 3.0 (CC BY 3.0), which permits unrestricted use, distribution, and reproduction in any medium, provided the original author and source are credited.

\section{ABSTRACT}

\begin{abstract}
A neuron sprouts an axon, and its branches to innervate many target neurons that are divergent in their functions. In order to efficiently regulate the diversified cells, the axon branches should differentiate functionally to be compatible with their target neurons, i.e., a function compatibility between presynaptic and postsynaptic partners. We have examined this hypothesis by using electrophysiological method in the cerebellum, in which the main axon of Purkinje cell projected to deep nucleus cells and the recurrent axons innervated the adjacent Purkinje cells. The fidelity of spike propagation is superior in the recurrent branches than the main axon. The capabilities of encoding spikes and processing GABAergic inputs are advanced in Purkinje cells versus deep nucleus cells. The functional differences among Purkinje's axonal branches and their postsynaptic neurons are preset by the variable dynamics of their voltage-gated sodium channels. In addition, activity strengths between presynaptic and postsynaptic partners are proportionally correlated, i.e., active axonal branches innervate active target neurons, or vice versa. The physiological impact of the functional compatibility is to make the neurons in their circuits to be activated appropriately. In conclusion, each cerebellar Purkinje cell sprouts the differentiated axon branches to be compatible with the diversified target cells in their functions, in order to construct the homeostatic and efficient units for their coordinated activity in neural circuits.
\end{abstract}

\section{INTRODUCTION}

In terms of functional interaction between the neurons, the efficient and coordinated relationships between presynaptic axons and postsynaptic neurons are compatible in their activity strengths, i.e., active axons innervate active neurons, or vice versa [1-3]. Otherwise, active axons drive inactive neurons leading to ineffective energy-cost, and inactive axons cannot activate active target neurons forming the silent partner. Moreover, each neuron sprouts an axon, and its axonal branches innervate numerous neurons. The sequential spikes generated on each neuron propagate through its axonal branches to the terminals and in turn regulate their diversified postsynaptic neurons [4-8]. The activity diversity of postsynaptic cells may require the functional state of presynaptic axonal branches to be differentiated, in order to form compatible relationship between presynaptic axonal branches and postsynaptic neurons in activity strengths, i.e., a functional compatibility between presynaptic and postsynaptic partners [2]. In other words, each neuron uses its axonal branches as the fractional diverters and regulates its 
postsynaptic cells appropriately. We have examined this hypothesis at the units that consisted of a Purkinje cell and its target neurons in the mouse cerebellum.

Each cerebellar Purkinje neuron sprouts a main axon and a few recurrent axonal branches that are GABAergic. The main axon innervates the neurons in the deep nucleus and the recurrent axons project to adjacent Purkinje cells [9-23]. In cerebellar slices, we have investigated whether the functional status was differential among Purkinje cell axon branches and among their target cells, as well as whether presynaptic and postsynaptic partners were functionally compatible. The functional states of presynaptic axonal branches were evaluated based on their abilities to propagate spikes and to release transmitters. The functions of the target cells innervated by these axonal branches were evaluated based on their capabilities to produce spikes and to respond to transmitter. In addition to analyzing their functional differentiation, we plotted a correlation of activity levels in each of presynaptic and postsynaptic partners. A proportional positive correlation implies the function compatibility between presynaptic and postsynaptic partners.

\section{RESULTS}

\section{Spike propagation is superior in recurrent axons than main axons of cerebellar Purkinje cells}

One of major functions for the axons is propagating sequential spikes [24]. Spike propagation fidelity was assessed by a ratio of the spikes propagated on axons to the spikes evoked at somata [25-27]. To monitor the spike propagation on the axons of each Purkinje cell, we evoked the spikes on its soma by depolarization pulses through a whole-cell pipette, and recorded the spikes propagated to the remote ends of its main axon and recurrent axon by two loose-patch pipettes simultaneously (Figure 1A). By comparing the spikes on soma (middle black traces in Figure 1B-D) and axonal branches (top red traces for recurrent axon and bottom blue ones for main axon), we can see that the spike propagation fails more on main axons than recurrent axons when the spikes are above 150 $\mathrm{Hz}$. The spike propagation fidelity versus spike frequency in Figure 1E illustrates that the frequency-dependent fidelity of spike propagation is higher in the recurrent

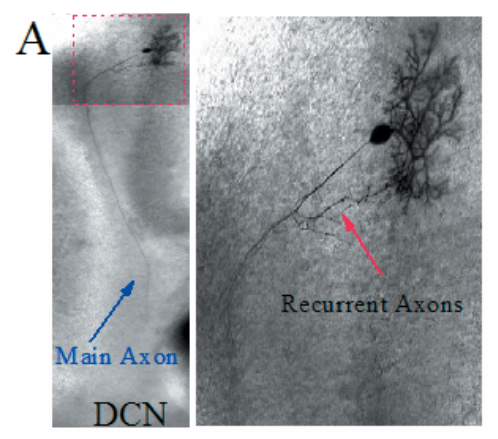

B

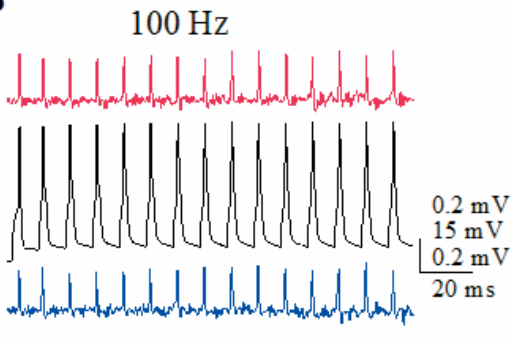

$\mathrm{C}$

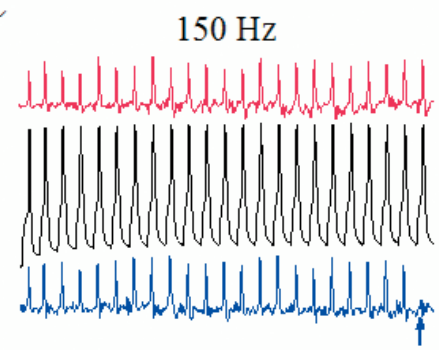

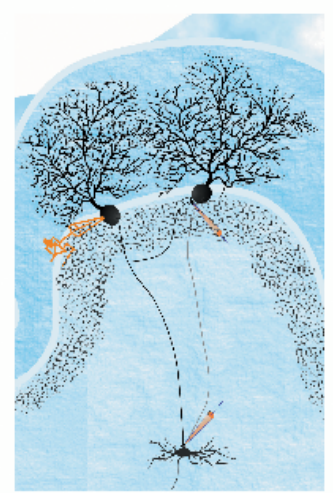
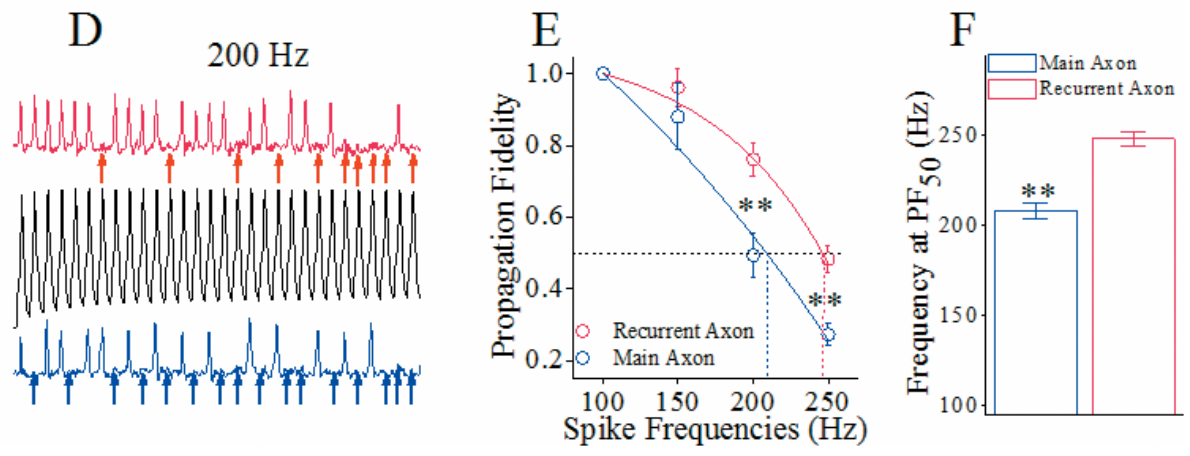

Figure 1: The spike propagation fidelity on the main axons and recurrent branches of cerebellar Purkinje cells (PC) is distinct. (A) Top-left panel shows a neurobiotin-labeled PC whose main axon extends to deep cerebellar nucleus (DCN) and recurrent axons to adjacent PCs. Top-right is an enlarged photo. Bottom shows whole-cell recording on PC as well as two loose-patch recordings on its main axon and recurrent axon. (B-D) Black traces illustrate somatic spikes induced by whole-cell recording pipette at PC (middle) and spikes recorded by loose-patch on recurrent axons (red traces in top) and on main axons (blues in bottom). Somatic spikes are induced by sequential depolarization pulses from $100 \mathrm{~Hz}$ to $250 \mathrm{~Hz}$. The arrows under loose-patch recorded signals show the failure of spike propagation on the axons. Calibration bars are $15 \mathrm{mV}$ (for whole-cell spikes) $/ 0.2 \mathrm{mV}$ (loose-patch spikes) and $20 \mathrm{~ms}$. (E) shows somatic spike frequency versus propagation fidelity on recurrent axons (red symbols) and main axons (blues; asterisks, $\mathrm{p}<0.01$, $\mathrm{n}=7$ ), i.e., the ratio of axonal spikes to somatic ones. Spike frequency at 50\% propagation fidelity ( $\mathrm{PF}_{50}$ showed as dash line) is defined as spike-propagation efficiency. (F) shows spike frequencies at $\mathrm{PF}_{50}$ on recurrent axon (red bar) and main axon (blue; asterisks, $\mathrm{p}<0.01$ ). 
axonal branches (red symbols) than the main axons (blue ones; $\mathrm{p}<0.01, \mathrm{n}=10$ pairs). Spike frequencies at $50 \%$ of propagation fidelity $\left(\mathrm{PF}_{50}\right)$ that merit spike propagation fidelity are $248 \pm 3.9 \mathrm{~Hz}$ on the recurrent axons and $208 \pm 4.4 \mathrm{~Hz}$ on the main axon (Figure 1F, $<<0.01$ ). The superior spike propagation on the recurrent axons versus the main axons indicates a functional differentiation of axonal branches from Purkinje cells.

The mechanism underlying the differences of spike propagation fidelity between axonal branches is likely based on the distinct dynamics of voltage-gated sodium channels (VGSC) on the two subcellular compartments since VGSCs play an essential role in spike propagation [27]. VGSCs' dynamics was assessed by measuring their refractory periods (RP) at the remote ends of recurrent and main axons with loose-patches (Methods). As spike propagation failure occurs in the late stage of spiking (Figure 1), we measured RPs after sequential spikes (Figure 2). RP values (Figure 2A) appear longer in main axons (blue trace) than recurrent axons (red). The statistical analysis indicates that RP values are $7.8 \pm 0.3 \mathrm{~ms}$ for main axons (blue bar in Figure 2B) and 5.92 $\pm 0.25 \mathrm{~ms}$ for recurrent axons ( $\mathrm{red}, \mathrm{p}=0.012, \mathrm{n}=11$ ). These relatively quick recoveries of VGSC inactivation and subsequent reactivation on recurrent axons lead to their greater spike propagation, compared with those on main axons.

This indication was studied by seeing an effect of rescuing VGSC function on spike propagation. As after-hyperpolarization (AHP) lowered spike threshold potentials and refractory periods $[27,28]$, we investigated the effect of AHP on spike propagation (Figure 3). AHP appears to raise spike propagation fidelity at its high frequency on main axons (Figure 3A-D). Figure $3 \mathrm{E}$ shows that AHP upregulates spike propagation fidelity on main axons closely to that on recurrent axons. This increase of spike propagation fidelity is due to strengthening VGSC reactivation, since AHP elevates the $\mathrm{dV} / \mathrm{dt}$ values of spike rising slope (Figure $3 \mathrm{~F}$ ), an index of synchronous activation of VGSCs [27]. This result also indicates that the lengths of main axon versus recurrent axon do not affect the difference in their fidelity of propagating spikes.

In summary, axon branches sprouted from cerebellar Purkinje cells are functionally differentiated, and the activity is superior in recurrent axons than main axons, which is based on the different dynamics of their VGSCs. We subsequently studied whether this functional differentiation was present in the target neurons of these axonal branches.

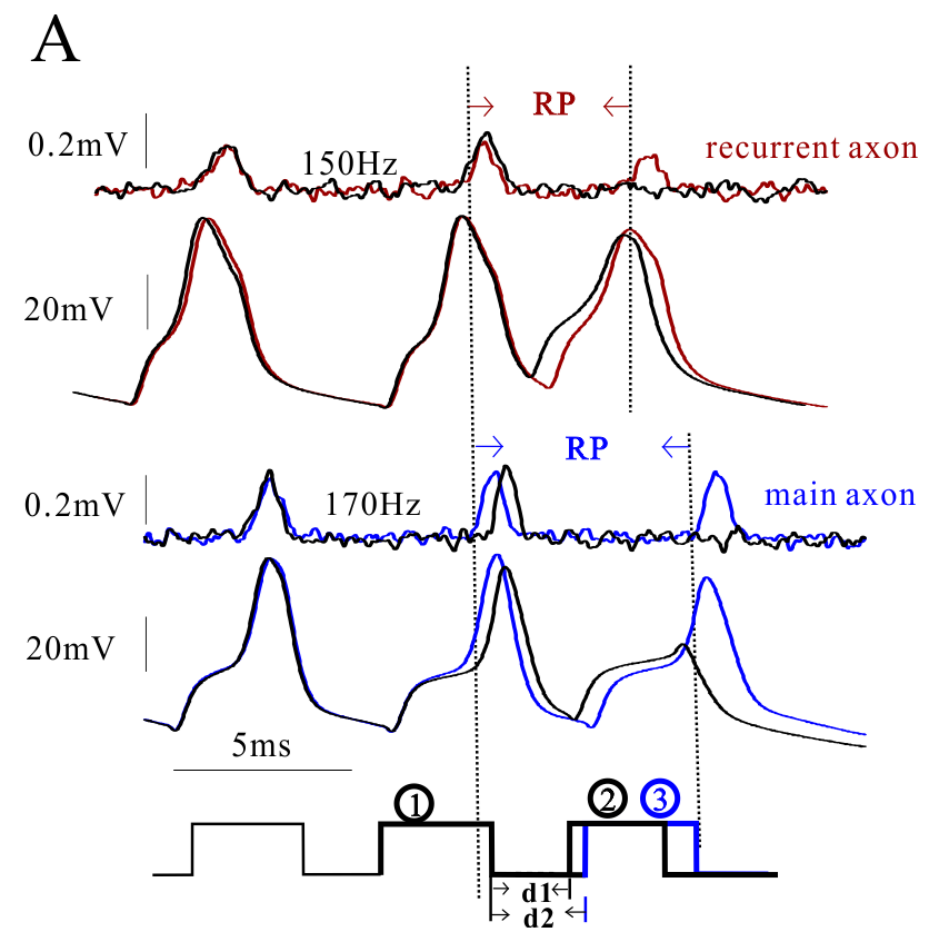

B

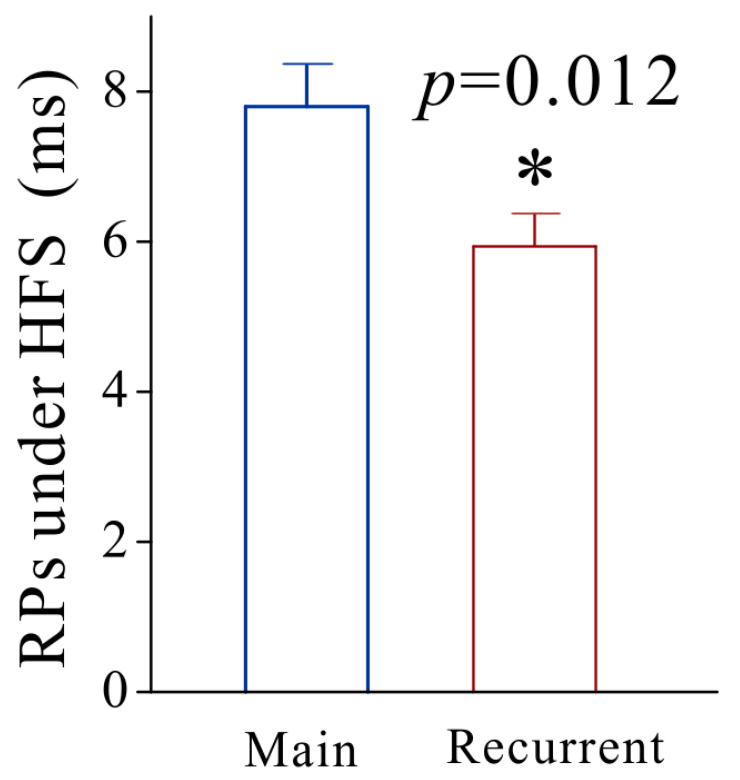

Figure 2: The refractory periods of voltage-gated sodium channels on the main axon and recurrent axons of cerebellar Purkinje cells (PC) is distinct. The refractory periods (RP) were recorded on the remote ends of these axonal branches by loosepatches while the spikes were induced at the PC somata by whole-cell recording. (A) illustrates the waveforms of RP measurements from the recurrent axon (red/black traces in top panels) and the main axon (blue/black traces in bottom panels). (B) shows the comparison of RP values from main axons (blue bar; $n=11$ ) and recurrent axons (red bar; $n=11, p=0.012$ ). It is noteworthy that Figure 2 A presents a single trace in order to have a clear demonstration of spikes. 


\section{Spiking capability is superior in Purkinje cells than deep nucleus cells in the cerebellum}

In Purkinje cells and deep nucleus cells that are the target cells of recurrent axons and main axons, respectively, we assessed their spiking ability by measuring relationship between stimulus intensities and spikes (input-output curve; [29]. Depolarization pulses (black traces in Figure 4A) appear to induce more spikes at Purkinje cells (reds) than deep nucleus cells (blues). Figure 4B shows spikes per second versus normalized stimuli for Purkinje cells (red symbols, $\mathrm{n}=10$ ) and deep nucleus cells (blues, $\mathrm{n}=10$ ). Spikes per second at $50 \%$ normalized stimuli $\left(\mathrm{NS}_{50}\right)$ that merit spiking capability are $26.53 \pm 1.65$ on Purkinje cells and $9.3 \pm 0.71$ on deep nucleus cells $(p<0.01$ in Figure $4 C)$. The cerebellar Purkinje cells possess higher ability to encode spikes, compared to deep nucleus cells. Therefore, Purkinje cell's target cells are functionally differentiated.

The input-output curve in spike production is presumably controlled by VGSC dynamics [30-32]. The differences of spiking ability on these two groups of the neurons may be due to differential VGSC dynamics. As spike refractory period (RP) is an index of VGSC dynamics [33-35], we measured RP at cerebellar Purkinje cells and deep nucleus cells (Figure 5). RP appears longer at deep nucleus cells than Purkinje cells (Figure 5A). RP values for spikes $1-4$ are $6.1 \pm 0.1,6.9 \pm 0.13,7.5 \pm 0.21$ and $7.9 \pm 0.25 \mathrm{~ms}$ at Purkinje cells, and are $8.8 \pm 0.4,10.5 \pm 0.39$, $12.2 \pm 0.5$ and $13.5 \pm 0.9 \mathrm{~ms}$ at deep nucleus cells. RP values for corresponding spikes in these two kinds of the neurons are statistically different (two asterisks, $\mathrm{p}<0.01$; $\mathrm{n}=10$ ).

In outline, the target cells of cerebellar Purkinje cells are functionally differentiated, and Purkinje cells are superior to deep nucleus cells, which is based on their different VGSC dynamics. In addition, we analyzed transmitter release to assess presynaptic axon function as well as receptor responsiveness to estimate postsynaptic neuronal function. The following experiments show whether presynaptic transmitter release and postsynaptic receptor function in main axons to deep nucleus cells versus recurrent axons to Purkinje cells are functionally differentiated.
A

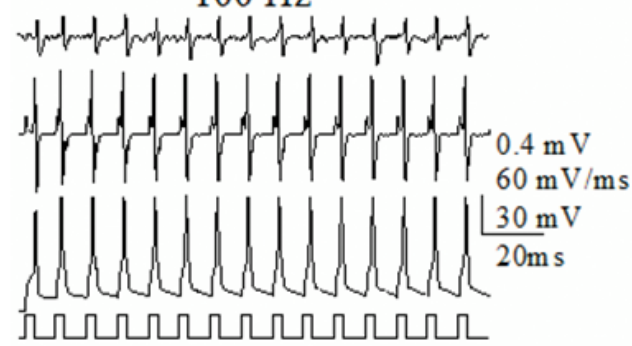

$\mathrm{C}$

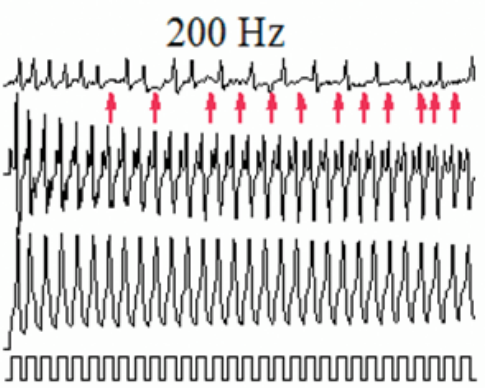

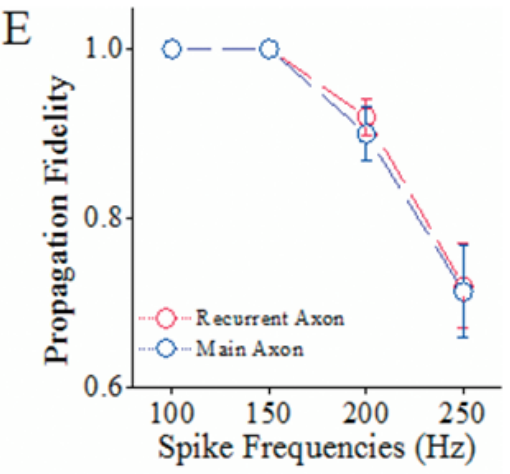

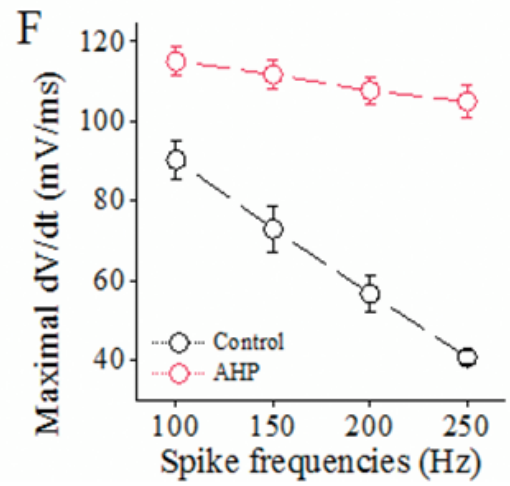

B

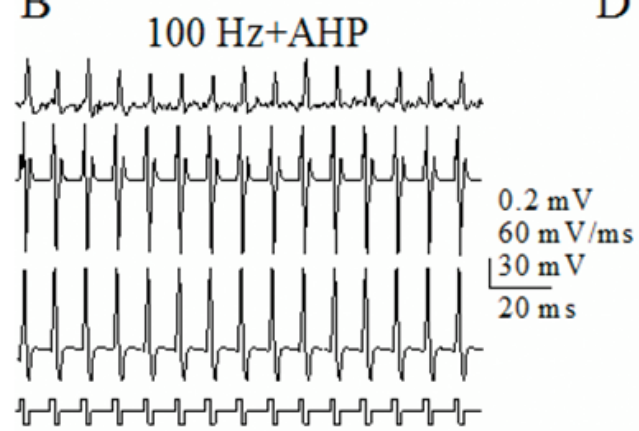

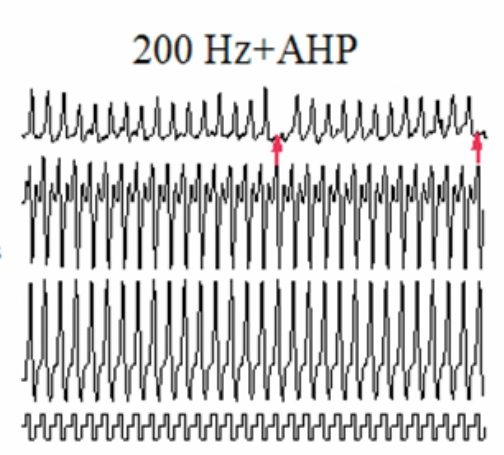

Figure 3: After-hyperpolarization raises spike propagation fidelity on main axons up to that on recurrent branches of cerebellar Purkinje cells (PC). (A-B) show sequential spikes induced by depolarization pulses ( $100 \mathrm{~Hz}$ in A) and the mixed pulses of depolarization and hyperpolarization (100 Hz in B). The traces from top to bottom are spikelets on main axon, dV/dt values, spikes on PC soma and pulse patterns. (C-D) show sequential spikes induced by depolarization pulses ( $200 \mathrm{~Hz}$ in C) and the mixes of depolarization and hyperpolarization $(200 \mathrm{~Hz}$ in D). The traces from top to bottom are spikelets on main axon, $\mathrm{dV} / \mathrm{dt}$ values, spikes on PC soma and pulse patterns. Red arrows indicate the failures of spike propagation. (E) shows somatic spike frequency versus propagation fidelity on the recurrent axons (red symbols) and main axons (blues; $\mathrm{n}=10$ ), i.e., a ratio of axonal spikes to somatic ones. (F) shows maximal dV/dt values versus spike frequencies on recurrent axons (red bar) and main axons (blue; asterisks, $\mathrm{p}<0.01 ; \mathrm{n}=10$ ). 


\section{GABA release and receptor responsiveness are superior in recurrent axons to Purkinje cells}

In the presynaptic and postsynaptic partners of main axons to deep nucleus cells versus recurrent axons to Purkinje cells, GABA release was assessed by analyzing the frequency of spontaneous inhibitory postsynaptic currents (sIPSC) and their receptor responsiveness to GABA was evaluated by the amplitude of sIPSCs [36, 37]. sIPSCs were recorded on cerebellar Purkinje cells and deep nucleus cells.

sIPSC amplitudes and frequencies appear to be higher on Purkinje cells than deep nucleus cells (Figure $6 \mathrm{~A}-\mathrm{B})$. Figure $6 \mathrm{C}$ shows cumulative probability versus inter-event intervals in Purkinje cells (red symbols; $n=10$ ) and deep nucleus cells (blues; $n=10$ ). sIPSC frequencies at $50 \%$ cumulative probability $\left(\mathrm{CP}_{50}\right)$ that merit GABA release are $6.78 \pm 0.62 \mathrm{~Hz}$ from recurrent axons and $3.1 \pm 0.3 \mathrm{~Hz}$ from main axons $(\mathrm{p}<0.01$; Figure $6 \mathrm{D})$. The superior GABA release from recurrent axons than main axons further implies a functional differentiation of axonal branches from Purkinje cells. Figure 6E shows cumulative probability versus sIPSC amplitudes in Purkinje cells (red symbols) than deep nucleus cells (blue). sIPSC amplitudes at $50 \%$ cumulative probability $\left(\mathrm{CP}_{50}\right)$ that merit GABA receptor responses are $24.1 \pm 2.1 \mathrm{pA}$ on Purkinje cells and $9.33 \pm 0.91 \mathrm{pA}$ on deep nucleus cells $(\mathrm{p}<0.01$ in Figure 6 F). The superior responses of Purkinje cells to GABA than of deep nucleus cells further indicates a functional differentiation of Purkinje's target cells.
The abilities of spike encoding and synaptic transmission in presynaptic and postsynaptic entities are differentiated. Compared the functional states of axonal branches and their target cells in the units of a Purkinje cell to postsynaptic neurons (Figures 1-6), we found that the activity strengths were superior in a pathway from recurrent axons to Purkinje cells than a pathway from main axon to deep nucleus cells. We subsequently examined whether the activity strengths between presynaptic and postsynaptic partners were compatible by analyzing their functional correlations.

\section{The functional states between axonal branches and their target neurons are linearly correlated}

In the analysis of the functional correlations between presynaptic and postsynaptic partners, spike frequencies at $\mathrm{PF}_{50}$ in each axonal branch were read from samples in Figure 1E; and spikes per second at $\mathrm{NS}_{50}$ in each target cell were from samples in Figure 4B. Figure 7A shows the relationship between spike propagation fidelity on recurrent axons and spiking ability on Purkinje cells (red symbols), as well as that between propagation fidelity on main axons and spiking ability on deep nucleus cells (blues). The linearly proportional correlations in their functional states indicate that the abilities of processing spikes in axonal branches and their target cells are compatible.

In the analysis of the functional correlations between presynaptic GABA release and postsynaptic
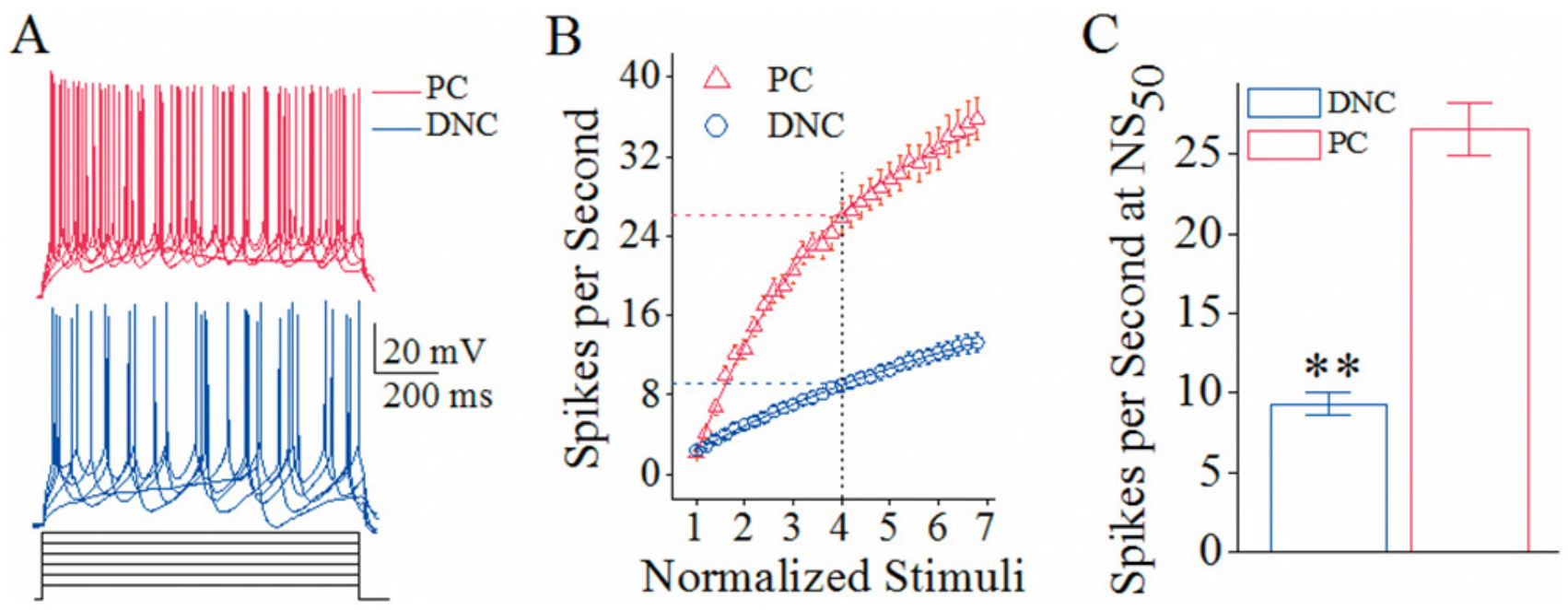

Figure 4: The spiking ability is higher at cerebellar Purkinje cells (PC) than deep nucleus cells (DNC). (A) Superimposed waveforms show sequential spikes induced by depolarization pulses in various intensities at a Purkinje cell (red traces) and deep nucleus cell (blue traces). Calibration bars are $20 \mathrm{mV}$ and $200 \mathrm{~ms}$. (B) illustrates spike per second versus normalized stimuli, i.e., input-output curves, for Purkinje cells (red symbols, $\mathrm{n}=10$ ) and deep nucleus cells (blues, $\mathrm{n}=10$ ). Spikes per second at $50 \%$ of normalized stimuli $\left(\mathrm{NS}_{50}\right)$ reflect the ability of encoding spikes. The normalized stimuli are based on the threshold intensity of evoke a spike during $200 \mathrm{~ms}$, and the step of intensity increase is $10 \%$ of threshold intensity. (C) shows spike per second at $\mathrm{NS}_{50}$ from Purkinje cells (red bar) and deep nucleus cells (blue; asterisks, $\mathrm{p}<0.01$ ). 

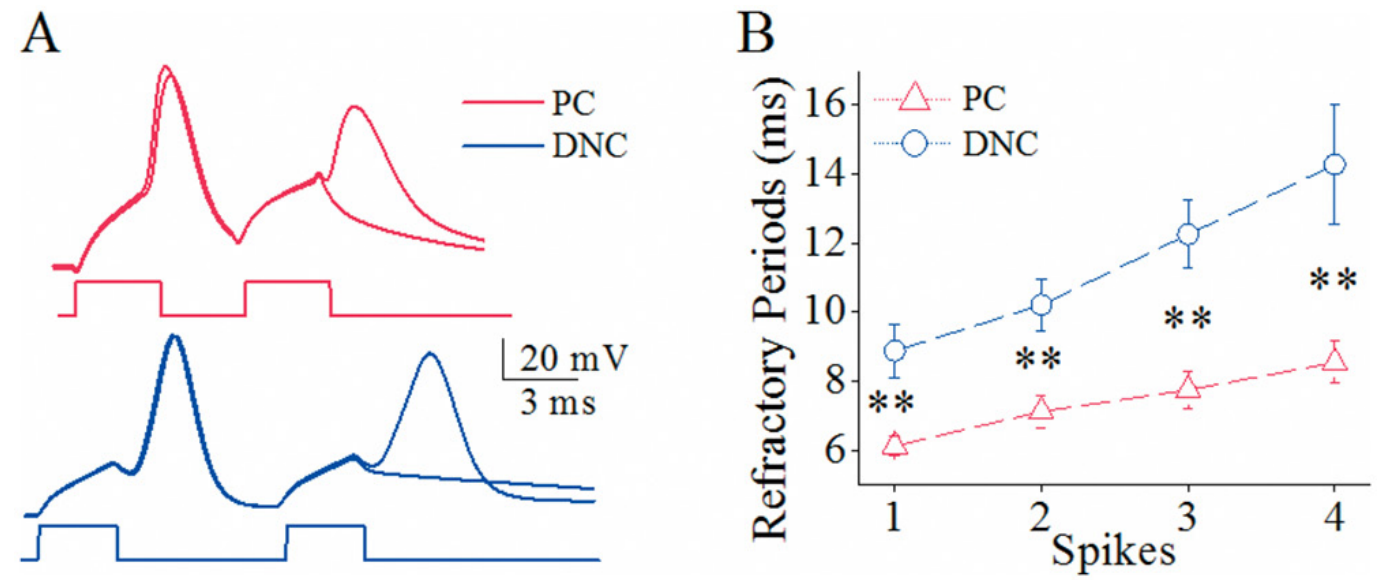

Figure 5: The spike refractory periods is shorter at cerebellar Purkinje cells (PC) than deep nucleus cells (DNC). (A) The superimposed waveforms illustrate longer refractory periods (RP) at a deep nucleus cell (blue traces) than a Purkinje cell (reds). (B) shows statistical data for RP values of spikes 1-4 at PCs (red symbols, $\mathrm{n}=10$ ) and DNCs (blues, $\mathrm{n}=10$; asterisks, $\mathrm{p}<0.01$ ).
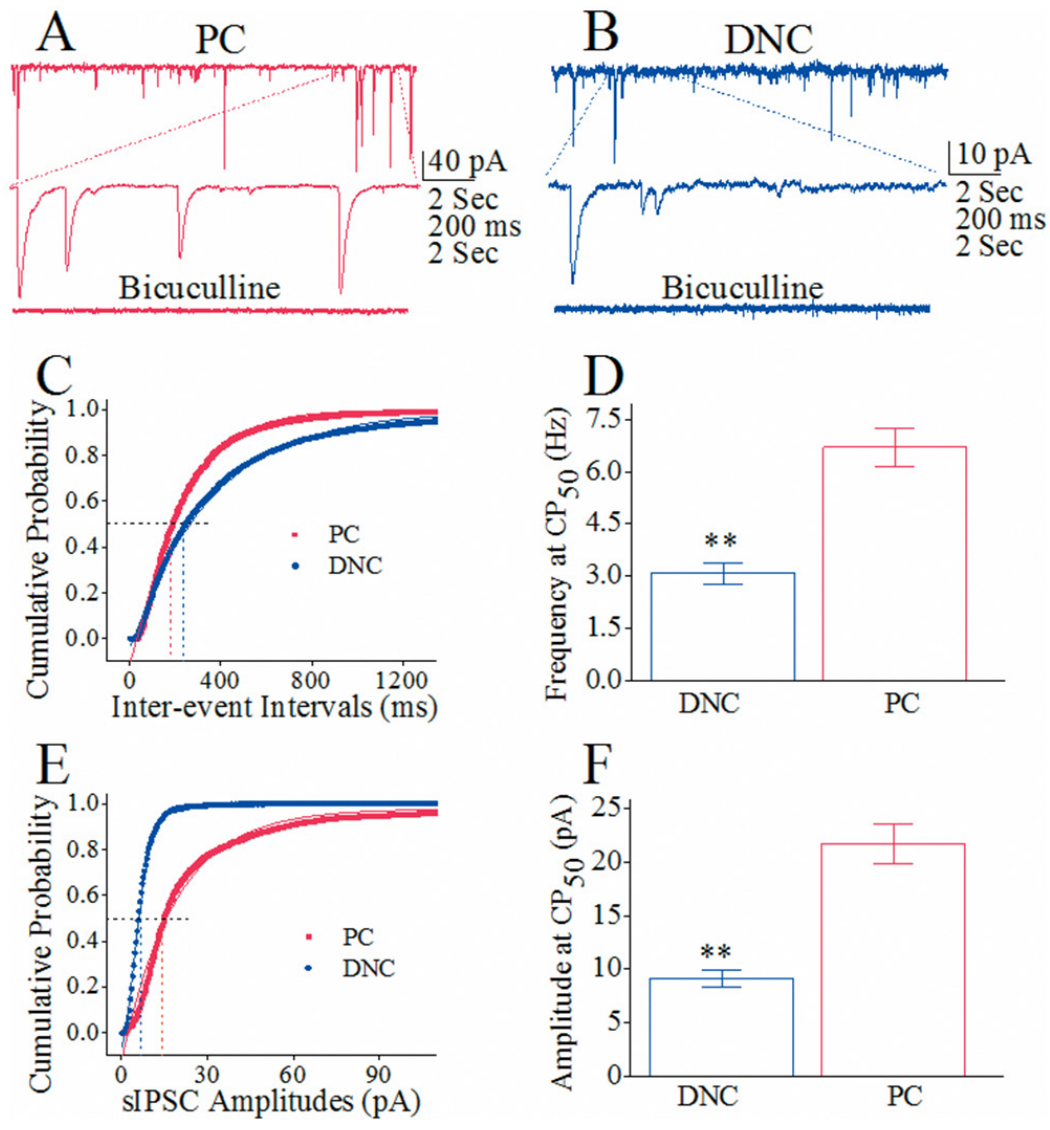

Figure 6: The comparison in the activity of GABAergic synapse on Purkinje cells (PC) and deep nucleus cells (DNC). The activities of GABAergic synapses are evaluated by recording sIPSCs on these cells under voltage-clamp in the presence of CNQX and D-AP5. (A) sIPSCs recorded from a PC in the control and presence of $10 \mu \mathrm{M}$ Bicuculline (bottom trace). (B) sIPSCs recorded from a DNC in the control and presence of Bicuculline (bottom trace). (C) Cumulative probability vs. inter-event intervals for DNCs (blue symbols, $\mathrm{n}=10)$ and PCs (red ones, $\mathrm{n}=10)$, in which $\mathrm{sIPSC}$ frequencies (1/inter-event intervals) at $50 \%$ of cumulative probability $\left(\mathrm{CP}_{50}\right)$ reflect presynaptic GABA release. (D) shows sIPSC frequencies at $\mathrm{CP}_{50}$ from recurrent axon (red bar) and main axon (blue bar; asterisks, $\mathrm{p}<0.01$ ). (E) illustrates cumulative probability versus sIPSC amplitudes for DNCs (blue symbols, $\mathrm{n}=10$ ) and PCs (reds, $\mathrm{n}=10$ ), where sIPSC amplitudes at $50 \%$ of cumulative probability $\left(\mathrm{CP}_{50}\right.$, dash line) present postsynaptic responsiveness. (F) shows sIPSC amplitudes at $\mathrm{CP}_{50}$ on Purkinje cells (red bar) and deep nucleus cells (blue bar; asterisks, $\mathrm{p}<0.01$ ). 
GABA receptor responses, sIPSC frequencies at $\mathrm{CP}_{50}$ were read from samples in Figure 6D; and sIPSC amplitudes at $\mathrm{CP}_{50}$ were read form Figure $6 \mathrm{~F}$ ). Figure $7 \mathrm{~B}$ illustrates the linearly proportional correlations between GABA release from recurrent axons and GABAR responses in Purkinje cells (red symbols), as well as between GABA release from main axons and GABA response in deep nucleus cells (blues). These linearly proportional correlations indicate that the presynaptic GABA release and postsynaptic GABAR responses are compatible.

In addition to the functional differentiation between the pathway from recurrent axons to Purkinje cells and the pathway from main axons to deep nucleus cells, the presynaptic and postsynaptic partners in each pathway are compatible in their activity strength. Our studies firstly reveal that the axonal branches from each cerebellum Purkinje cell are functionally differentiated to be compatible with their postsynaptic partners. To validate this functional compatibility between presynaptic and postsynaptic partners, we have done these analyses in younger rats (postnatal day 8) and obtained the similar results (please see Supplementary Figures 1-4 in supporting data). The functional compatibility between presynaptic and postsynaptic partners in the different ages of animals indicates its natural presence and importance.

\section{Functional compatibility between axonal branches and target cells grants neural homeostasis}

Physiological impacts for functional compatibility between presynaptic and postsynaptic partners may enable each neuron through its differentiated axonal branches to regulate their target cells properly, and their target cells to work efficiently for neuronal circuit homeostasis. We examined this hypothesis by a computational simulation. Purkinje cells and deep nucleus cells receive excitatory and inhibitory inputs. The strengths of GABAergic synapses in different presynaptic and postsynaptic partners were read from Figure 6. The abilities of encoding spikes in different target neurons were from Figure 4. The fidelities of spike propagation for main axons and recurrent axons were from Figure 1E.

Figure $8 \mathrm{~A}-\mathrm{B}$ illustrates the results from presynaptic and postsynaptic compatibility (left panel in 8A). The right-top panel in $8 \mathrm{~A}$ shows spike patterns at Purkinje cells that are functionally compatible to recurrent axons. The right-bottom in 8A shows spiking patterns at deep nucleus cells that are compatible to main axons. Spike frequencies vs. number of Purkinje cells (red trace) or deep nucleus cells (blue) are plotted in Figure 8B. On the other hand, if the functions of recurrent branches and main axons exchange (left panel in Figure 8C), the spiking ability of Purkinje cells is upregulated to be synchrony (right-top panel) and the function of deep nucleus cells is almost silent (right-bottom). Statistical data are shown in Figure 8D. In addition to the firing frequency for Purkinje cells at $150 \mathrm{~Hz}$, we also see the compatibility between presynaptic and postsynaptic partners when the firing rate of Purkinje cells is at $100 \mathrm{~Hz}$ (Figure 8E-F). The functional compatibility between the presynaptic and postsynaptic partners makes cerebellar networks coordinated; otherwise, the network neurons would be overexcited or functionally silent.

\section{DISCUSSION}

The axon from a cerebellar Purkinje cell sprouts main axon and recurrent axons, which innervate deep nucleus cells and Purkinje cells, respectively. In this unit,
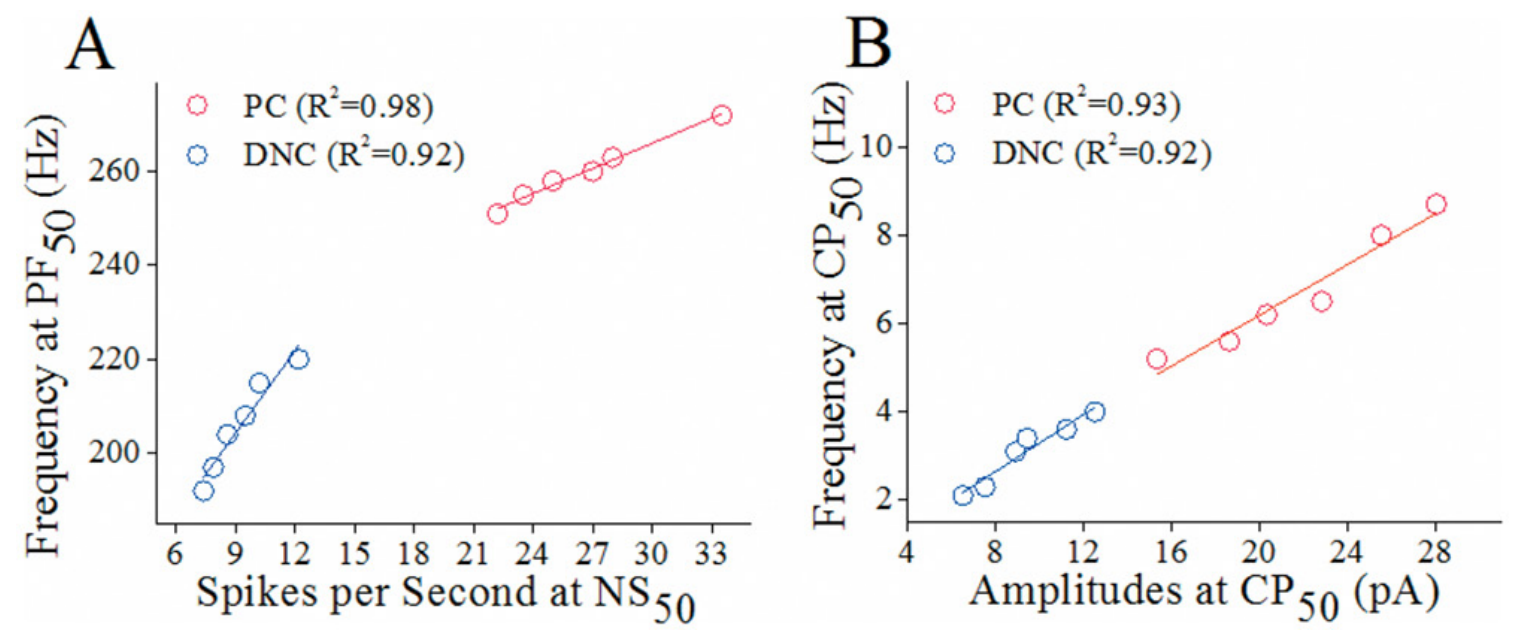

Figure 7: The correlations of functional status between presynaptic axonal branches of Purkinje cells (PC) and their target cells. (A) shows the linear correlations between presynaptic spike frequencies at $\mathrm{PF}_{50}$ and postsynaptic spikes per second at $\mathrm{NS}_{50}$ for recurrent branches-to-PCs (red symbols) and main axons-to-DNCs (blues) from PND 15 rats. (B) shows linear correlations between sIPSC frequencies and amplitudes at $\mathrm{CP}_{50}$ for PCs (red symbols) and DNCs (blues) from PND 15 rats. 
the functional states of presynaptic axonal branches and of postsynaptic cells are differentiated. This differentiation makes a compatible relationship between presynaptic and postsynaptic partners (Figures 1-7). The functional compatibility makes active cells receiving more inhibitions, or vice versa, so that the neurons in each unit are activated appropriately (Figure 8). Our study reveals a new principle for cerebellar neural circuits to be functional in an optimal manner. Each neuron through its functiondifferentiated axon branches regulates divergent target neurons efficiently. The functional compatibility between the presynaptic and postsynaptic partners enables each microcircuit being homeostatic and entire circuits being coordinated for well-organized behaviors.

The cerebellar Purkinje cells produce high frequency spikes [38-41]. Their axonal branches innervate the divergent targets, e.g., deep nucleus cells and other Purkinje cells [42]. A connection divergence from a neuron to multiple cells expands the uses of its computational codes. In terms of their functional relationships, if inhibitory axonal branches inhibit inactive cells to be non-functional, the neural networks containing many silent neurons are inefficient. On the other hand, if inhibitory axonal branches innervate active cells, they may not inhibit these active cells, leading to neuronal synchrony in neural networks. The functional compatibility of presynaptic and postsynaptic partners makes postsynaptic cells to be regulated well and cerebellar neural network built optimally. In order to fulfill this goal, axonal branches from a Purkinje cell should be functionally differentiated to match their partner neurons. The functional compatibility in cerebellar network may play important roles in the cerebellum functions, such as behavioral coordination and flexibility [43].

The mechanisms underlying the functional differentiation and compatibility between presynaptic and postsynaptic partners are based on the various dynamics of voltage-gated sodium channels on these axonal branches and their target neurons (Figures 2 and 5) as well as of transmitter release and receptor responsiveness on these entities (Figure 6). It remains to be studied how the presynaptic and postsynaptic mechanisms in compatible manner are preset and regulated, whether the axonal branches and target cells form their synaptic connections by recognizing their functional compatibility or they reform coordinately after synapse formation, and whether the functional compatibility between presynaptic and postsynaptic partners is upheld during neural plasticity through anterograde and retrograde interaction.
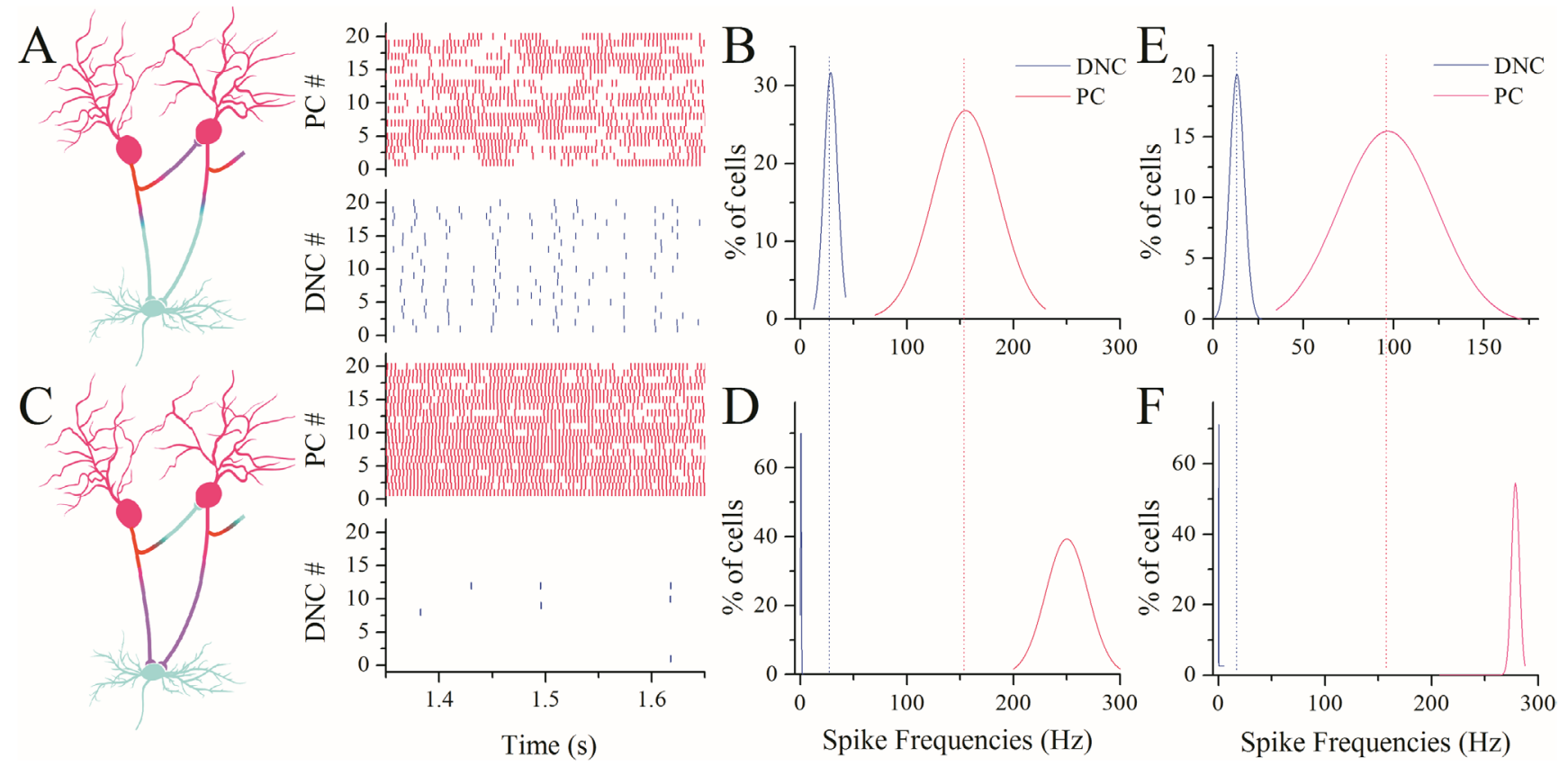

Figure 8: Functional compatibility between presynaptic and postsynaptic patterns makes the function of network neurons efficient. (A) shows spike patterns at Purkinje cells (red vertical bars, top panel) and deep nucleus cells (blues, bottom) when recurrent branches vs. PCs and main axons vs. DNCs are functionally compatible (left panel, hot axons innervate active neurons, or vice versa). (B) shows the percentages of neurons vs. spike frequencies at PCs (red curve) and DNCs (blue). (C) shows spike patterns at Purkinje cells (reds, top) and deep nucleus cells (blues) when presynaptic functions are changed to recurrent axons-to-DNCs and main axon-to-PCs, i.e., functional incompatibility (left panel). (D) shows the percentages of neurons vs. spike frequencies at PCs (red curve) and DNCs (blue), where DNCs shifts toward functional silence and PCs toward overexcitation. (E-F) illustrates the percentages of neurons versus spike frequency $(100 \mathrm{~Hz})$ at PCs (reds) and DNC (blues) under the conditions of compatibility (E) and incompatibility (F) between presynaptic and postsynaptic partners. 
Table 1: Physiological properties for cerebellar Purkinje cells and deep nucleus cells

\begin{tabular}{lccccc}
\hline \multirow{2}{*}{ Physiological properties } & \multicolumn{2}{c}{ Purkinje cells } & & \multicolumn{2}{c}{ Deep nucleus cells } \\
\cline { 2 - 3 } \cline { 5 - 6 } & Biological & Model & & Biological & Model \\
\hline $\mathrm{C}_{\mathrm{m}}(\mathrm{pF})$ & $469.3 \pm 18.1$ & 475 & & $124.7 \pm 7.4$ & 125 \\
$\mathrm{R}_{\mathrm{m}}(\mathrm{M} \Omega)$ & $121.8 \pm 4.0$ & 120 & & $217.5 \pm 7.2$ & 218 \\
$\mathrm{RMP}(\mathrm{mV})$ & $-60.5 \pm 0.7$ & -60.5 & & $-49.2 \pm 1.0$ & -50 \\
AP threshold potentials $(\mathrm{mV})$ & $-45.5 \pm 1.8$ & -45.5 & & $-26.2 \pm 2.3$ & -26.2 \\
\hline
\end{tabular}

Table 2: Functional dynamics of ligand-gated receptor channels in the synapses

\begin{tabular}{lcccc}
\hline Types of receptors & $\mathbf{g}_{\max }(\mathbf{n S})$ & $\boldsymbol{\tau}_{\mathbf{1}}(\mathbf{m s})$ & $\boldsymbol{\tau}_{\mathbf{2}}(\mathbf{m s})$ & $\mathbf{E}_{\text {rev }}(\mathbf{m V})$ \\
\hline AMPA & 4 & 1 & 2 & 0 \\
NMDA & $19-27$ & 0.67 & 80 & 0 \\
GABA $_{\mathbf{A}}$ & $17-150$ & 1 & 4 & -70 \\
\hline
\end{tabular}

Table 3: Parameters of action potential propagation fidelity

\begin{tabular}{lcc}
\hline Types of cells & $\mathbf{f}_{\mathbf{5 0}}$ & B \\
\hline Purkinje cell & $255 \pm 2.18$ & $0.0048 \pm 0.000045$ \\
Deep nucleus cell & $220 \pm 6.16$ & $0.0052 \pm 0.00014$ \\
\hline
\end{tabular}

It is noted that cerebellar Purkinje cells produce action potentials with a wide range of frequency from 50 to $250 \mathrm{~Hz}$ in vivo [38-41,44]. Based on this information, the evoked spikes at the cerebellar Purkinje cells in our experiments were from 100 to $250 \mathrm{~Hz}$ in their frequencies, and the computational simulation matched this range of spike frequency (100-150 Hz in Figure 5). The indications in our study about the reliability of spike propagation and the compatibility of presynaptic versus postsynaptic partners are still suitable for establishing the concept under physiological conditions, in spite of closing to the high end of spike frequency.

In terms of neurons and synapses, many studies were focused on their plasticity and homeostasis [45-51]. The functional compatibility between presynaptic and postsynaptic cell partners should also be an important feature that makes cellular interaction coordinated and efficient, i.e., a principle for the optimal activities of neuronal networks. It is noteworthy that the different kinds of cells in tissue interact one another. The compatibility and coordination in their activity levels are critically important to maintain their appropriate interaction as well as not to waste the energy due to any difference in their activity levels.

It is noteworthy that several points should be stressed. In addition to voltage-gated sodium channels, voltage-dependent potassium channels are presumably to regulate spike refractory periods and neuronal excitability. Their differences can explain the functional differentiations of presynaptic axonal branches and their postsynaptic neurons. As the effect of potassium channels on refractory periods is done through sodium channels [28], the involvement of potassium channels in the functional differentiations, if it is present, may be fulfilled based on voltage-gated sodium channels. In addition to deep nuclear cells and Purkinje cells, the axonal branches of cerebellar Purkinje neurons terminate onto other types of postsynaptic neurons [17-19]. Whether the functional differentiation and compatibility are present on these units and partners should be done in our future studies.

The axonal branches that are functionally differentiated to match postsynaptic neurons constitute a fractional diverter without the need of intermediate components. This simplified design in the brain may be useful to build the compatibility among basic units in electronic circuits and social networks for their wellorganized performance.

\section{MATERIALS AND METHODS}

All experiments were performed in accordance with the relevant guidelines and regulations by the Administration Office of Laboratory Animals at Beijing China. All experimental protocols were approved by the 
Institutional Animal Care Unit Committee (IACUC) in the Administration Office of Laboratory Animals at Beijing China (B10831).

Brain slices and neurons: All experiments were approved by the Institutional Animal Care Unit Committee in Administration Office of Laboratory Animals Beijing China (B10831). Cerebellar sagittal slices $(400 \mu \mathrm{m})$ were prepared from Wistar rats in postnatal days (PND) 8 or 14 15 under the anesthesia by injecting chloral hydrate $(300 \mathrm{mg} / \mathrm{kg}$ ) for decapitation by a guillotine. Slices were cut by Vibratome in a modified and oxygenized $\left(95 \% \mathrm{O}_{2}\right.$ and $5 \% \mathrm{CO}_{2}$ ) artificial cerebrospinal fluid (mM: $124 \mathrm{NaCl}$, $3 \mathrm{KCl}, 1.2 \mathrm{NaH}_{2} \mathrm{PO}_{4}, 26 \mathrm{NaHCO}_{3}, 0.5 \mathrm{CaCl}_{2}, 5 \mathrm{MgSO}_{4}$, and 10 dextrose and 5 HEPES; $\mathrm{pH} \mathrm{7.4)} \mathrm{at} 4^{\circ} \mathrm{C}$, and were held in the normal oxygenated ACSF (mM: $126 \mathrm{NaCl}$, $2.5 \mathrm{KCl}, 1.25 \mathrm{NaH}_{2} \mathrm{PO}_{4}, 26 \mathrm{NaHCO}_{3}, 2 \mathrm{CaCl}_{2}, 2 \mathrm{MgSO}_{4}$ and 25 dextrose; $\mathrm{pH} 7.4) 35^{\circ} \mathrm{C}$ for $1 \sim 2$ hours before electrophysiological experiments. A slice was transferred to a submersion chamber (Warner RC-26G) and perfused by normal ACSF at $31^{\circ} \mathrm{C}$ for whole cell and loose patch recordings [23, 27, 29, 52-54].

Cerebellar Purkinje cells (PC) were identified based on their morphology and spiking properties. Purkinje cells in the slices (somata above $40 \mu \mathrm{m}$ ) for the wholecell recordings were located at the border between molecular layer and granule cells. They were infused with a fluorophore Alexa-488 (5 $\mu \mathrm{M}$ in the recording pipettes) under a DIC-fluorescent microscope (Nikon, FN-E600) to show typical dendrites and to guide the tracing of axonal branches for loose-patch recordings. The Purkinje cells were also labeled by neurobiotin (Figure 1A). These Purkinje cells demonstrated fast spikes with no obvious adaptation in their amplitudes and frequencies [55-59].

Cerebellar deep nucleus was located at a convergent area of cerebellar lobes including excitatory and inhibitory neurons, and was innervated by the main axons of Purkinje cells $[15,19,59]$. Deep nucleus cells (DNC) appeared round soma and multiple processes under the DIC microscope (Nikon, FN-E600). The neurons in our analyses appeared fast spiking with no adaptation in the amplitudes and frequency, the typical properties for the interneurons [56, 59-64]. It is noteworthy that the reason to select inhibitory deep nucleus cells and Purkinje cells innervated by PC axonal branches in our study is to have the similar features of target cells, such that the differences in spiking propagation among PC axonal branches and in synaptic transmission at the pairs of PC-DNC and PC-PC are less likely affected by these PC-target cells.

Electrophysiological studies: Sequential spikes in Purkinje cells propagate on their main axons and recurrent branches. Each experiment in a Purkinje cell was conducted by whole-cell recording on its soma and two loose-patch recordings on the remote ends of its main and recurrent axons simultaneously (Figure 1A). The electrical signals were recorded by MultiClamp-700B amplifier (Axon Instrument Inc, CA USA) and inputted into pClamp-10 in $50 \mathrm{kHz}$ sampling rate. Transient capacitance was compensated and output bandwidth was $3 \mathrm{kHz}$. Pipette solution for recording spikes included (mM) $150 \mathrm{~K}$-gluconate, $5 \mathrm{NaCl}$, 0.4 EGTA, $4 \mathrm{Mg}$-ATP, 0.5 Tris- GTP, 4 Na-phosphocreatine and 10 HEPES (pH 7.4 adjusted by $2 \mathrm{M} \mathrm{KOH}$ ). The solution for loose-patch recording was ACSF (please see above). An osmolarity of pipette solutions made freshly was $295-305 \mathrm{mOsmol}$. The pipette resistance was $8 \sim 10 \mathrm{M} \Omega[65,66]$.

In studying spike propagation on the axonal branches of Purkinje cells, we injected depolarization pulses in various durations and intervals into their somata to induce spikes at 100,150, 200 and $250 \mathrm{~Hz}$. The spikes induced in these frequencies were based on the facts that cerebellar Purkinje cells fired high frequency spikes up to $500 \mathrm{~Hz}[38-41,44]$. The spikes propagated to axonal terminals were recorded by loose-patch at the remote ends of main axons and recurrent branches. Synchronous spikes at the soma and axon branches indicated signals from a Purkinje cell. The efficacy to propagate the spikes on the axons of Purkinje cells was assessed by a ratio of spikes recorded at axonal terminals to those induced on soma.

The influences of the axonal branches of Purkinje cells on their target neurons were evaluated by recording the events of GABAergic inhibitory synapses at adjacent Purkinje cells and deep nucleus cells. Spontaneous inhibitory postsynaptic currents (sIPSC) were recorded under a voltage-clamp [36, 67-70]. With the pipette solution composed of (mM) $135 \mathrm{~K}$-gluconate, $20 \mathrm{KCl}, 4$ $\mathrm{NaCl}, 10$ HEPES, 0.5 EGTA, $4 \mathrm{Mg}$-ATP, and 0.5 TrisGTP, the Nernst's equation defined reversal potential at $-43 \mathrm{mV}$ for this $\mathrm{Cl}^{-}$concentration, consistent with our recorded values. When cellular membrane potentials were held at $-70 \mathrm{mV}$, sIPSCs were inward (down-fluctuation). 6-Cyano-7-nitroquinoxaline-2,3-(1H,4H)-dione $\quad(10$ $\mu \mathrm{M})$ and D-amino-5-phosphonovanolenic acid $(40 \mu \mathrm{M})$ were added in the ACSF to block ionotropic glutamate receptors $[36,71,72]$ and to record GABAergic IPSCs in isolation. At the end of each experiment, bicuculline (10 $\mu \mathrm{M})$ was washed into the slices to test whether synaptic responses were mediated by GABA $\mathrm{R}$. sIPSC amplitudes represent the responsiveness of $\mathrm{GABA}_{\mathrm{A}} \mathrm{R}$, while sIPSC frequency reflects the innervation of GABAergic axons and the probability of GABA release. As the probability of GABA release from each axon is $100 \%$ (please see a paired-recording from an interneuron to another neuron in Supplementary Figure 2), sIPSC frequency may present the innervation of GABAergic axons. It is noteworthy that the recorded sIPSCs on Purkinje cells are likely generated from the axonal innervation from neighboring PC because the following reasons. The inhibitory synapses on cerebellar Purkinje cells dominantly come from neighboring PC than basket cells [73]. The recurrent axons of Purkinje cells terminate on the cell body of Purkinje cells, while the axons of basket cells terminate onto the dendrites of Purkinje cells, i.e., the propagations of PC- 
PC IPSCs to recording sites are less affected by passive membrane property. The frequency of spontaneous spikes is higher in cerebellar Purkinje cells than basket cells [38-41].

The capability of the neurons to produce spikes was assessed by measuring relationship between stimulus intensities and spikes (the input-output curve; [29, 31, 32, 74-76]. The capability of firing spikes was measured by counting spikes per second, while the stimulus intensities (i.e., depolarization pulses in one second) were increased in a step-by-step manner. As different neurons showed different excitability, the stimulus intensities were normalized for the data average. To each of the neurons, the spike threshold was detected by increasing stimulus intensities until seeing 50\% chance to produce single spike by this stimulus. Absolute refractory periods (ARP) during the sequential spikes were measured by injecting paireddepolarization pulses ( $3 \mathrm{~ms}$ in duration and 1.2 times above threshold stimulus intensity, showed in Figure 2C) into the neurons after sequential spikes induced by a series of pulses ( $3 \mathrm{~ms}$ in duration and $200 \mathrm{~Hz}$ in frequency). By changing inter-pulse intervals, we defined ARP as the time from a complete spike to its subsequent spike at 50\% probability $[8,35,46,52]$. If the spikes during relative refractory period in the somata of Purkinje cells were able to be propagated to recurrent axon terminal but not main axon terminal, ARP would be longer in the main axons than recurrent axons.

The data were analyzed if the recorded neurons had resting membrane potentials more negative than -60 $\mathrm{mV}$ and action potentials at least $75 \mathrm{mV}$ in amplitudes. The criteria for the acceptation of each experiment also included less than $5 \%$ changes in resting membrane potential, spike magnitude, input and seal resistance. The values of spike input-outputs and sIPSCs are presented as mean \pm SE. As experiments for different spike frequencies and control versus various treatments were conducted in the given cells, the statistical comparisons between groups are done by paired t-test.

Neurobiotin staining for cerebellar cells: Pipette solutions for whole-cell recordings included $0.2 \%$ neurobiotin, which were back-filled into the recording pipettes whose tips contained the standard solution. After electrophysiological study, the slices were rapidly placed into $4 \%$ paraformaldehyde in $0.1 \mathrm{M}$ phosphate buffer solution (PBS) for fixation at $4{ }^{\circ} \mathrm{C}$ about 48 hours. The slices were incubated in avidin and horseradish peroxidase (Vectastain $\mathrm{ABC}$ ) for 3 hours, and then $1 \% \mathrm{DAB}-\mathrm{CoCl} 2$ (Sigma) $1 \mathrm{~min}$ for staining neurobiotin-filled cells. This reaction was stopped by PBS [65]. Neurobiotin-stained cells were photographed under the DIC of the confocal microscope (Olympus FV-1000, Japan).

Computational simulation for neuronal activity in the cerebellum was done in NEURON (v7.1). Purkinje cells and deep nuclei cells in this study were innervated by excitatory and inhibitory synapses $[10,11,13,15,17$,
20]. In addition to the excitatory axons of parallel and mossy fibers, each Purkinje cell received inhibitory inputs from recurrent branches of 4 5 adjacent Purkinje cells. The deep nuclei cells received inhibitory inputs from main axons of Purkinje cells. These neurons in the simulated network also received excitatory inputs from other areas in the central nervous system.

The factors inputted into the simulation were based on the properties of well-known network cells in the cerebellum and of inhibitory cells from our experiments. Each neuron in the simulated network was thought asan integrated-fire cell model in single compartment. Excitatory synaptic events were as steady inter-event intervals $(5 \sim 10 \mathrm{~ms})$. Functional properties for individual neurons to be inputted in a simulated network were based on our experimental data (Table 1).

To a role of ligand-gated ion channels in synaptic transmission, AMPAR and NMDAR mediated excitatory synapse activation, and $\mathrm{GABA}_{\mathrm{A}} \mathrm{R}$ works for inhibitory synapses. Postsynaptic conductance was function as a sum of two exponentials (Equation 1) [77]. The values of synaptic conductance inputted into our simulated network were listed in Table 2 [78].

$$
g_{S y n}(t)=\bar{g} *\left(\frac{\tau_{1} \tau_{2}}{\tau_{1}-\tau_{2}}\right) *\left(e^{-\frac{\tau}{\tau_{1}}}-e^{-\frac{\tau}{\tau_{2}}}\right)
$$

In our simulation about the fidelity of spike propagation on axons in response to spike frequency, a relationship between spike frequency and propagation fidelity followed Equation 2, whose values were taken from Figure 1E. In this equation, f50 represents spike frequency caused $50 \%$ failure of action potential propagation and $\mathrm{b}$ is a constant. The parameters of Equation 2 were listed in Table 3.

$$
p(f)=\left\{\begin{array}{lr}
1 & f<f_{50}+\frac{1}{b} \\
b\left(f_{50}+\frac{2}{b}-f\right) & f_{50}+\frac{1}{b} \leq f \leq f_{50}+\frac{2}{b} \\
0 & f>f_{50}+\frac{2}{b}
\end{array}\right.
$$

\section{Author contributions}

Yang, Chen and Ge worked on experiments and data analyses, Qian worked on computational simulation, Chen drawn illustration in bottom panel of Figure 1A and Wang contributed to project design and paper writing.

\section{ACKNOWLEDGMENTS}

We thank Dr. David Linden's critical reading and suggestions before submission. This study is funded by the grants from National Basic Research Program 
(2013CB531304 and 2016YFC1307101) and Natural Science Foundation China (81671071 and 81471123) to Jin-Hui Wang.

\section{CONFLICTS OF INTEREST}

All authors have read and approved the final version of manuscript, and claimed no conflicts interest.

\section{REFERENCES}

1. Pelkey KA, McBain CJ. Target-cell-dependent plasticity within the mossy fibre-CA3 circuit reveals compartmentalized regulation of presynaptic function at divergent release sites. J Physiol. 2008; 586: 1495-502. https://doi.org/10.1113/jphysiol.2007.148635.

2. Wang JH, Yang Z, Qian H, Chen N. Functional compatibility between Purkinje cell axon branches and their target neurons in the cerebellum. Biophys J. 2013; 104: 330a. http://dx.doi.org/10.1016/j.bpj.2012.11.1830.

3. Wang JH, Cui S. Associative memory cells: formation, function and perspective. F1000Res. 2017; 6: 283. https:// doi.org/10.12688/f1000research.11096.2.

4. Grillner S, Markram H, Schutter ED, Silberger G, LeBeau FEN. Microcircuits in action - from CPGs to neocortex. Trends Neurosci. 2005; 28: 525-33.

5. Markram H, Toledo-Rodriguez M, Wang Y, Gupta A, Silbergerg $\mathrm{G}, \mathrm{Wu} \mathrm{C}$. Interneurons of the neocortical inhibitory system. Nat Rev Neurosci. 2004; 5: 793-807.

6. Plazas PV, Nicol X, Spitzer NC. Activity-dependent competition regulates motor neuron axon pathfinding via PlexinA3. Proc Natl Acad Sci U S A. 2013; 110: 1524-9. https://doi.org/10.1073/pnas.1213048110.

7. Silberberg G, Grillner S, LeBeau FEN, Maex R, Markram H. Synaptic pathways in neural microcircuits. Trends Neurosci. 2005; 28: 541-51.

8. Wang JH, Wei J, Chen X, Yu J, Chen N, Shi J. The gain and fidelity of transmission patterns at cortical excitatory unitary synapses improve spike encoding. J Cell Sci. 2008; 121: 2951-60.

9. De Zeeuw CI, Berrebi AS. Postsynaptic targets of Purkinje cell terminals in the cerebellar and vestibular nuclei of the rat. Eur J Neurosci. 1995; 7: 2322-33.

10. D'Angelo E, Mazzarello P, Prestori F, Mapelli J, Solinas S, Lombardo P, Cesana E, Gandolfi D, Congi L. The cerebellar network: from structure to function and dynamics. Brain Res Rev. 2011; 66: 5-15. https://doi.org/10.1016/j. brainresrev.2010.10.002.

11. Foust A, Popovic M, Zecevic D, McCormick DA. Action potentials initiate in the axon initial segment and propagate through axon collaterals reliably in cerebellar Purkinje neurons. J Neurosci. 2010; 30: 6891-902. https://doi. org/10.1523/JNEUROSCI.0552-10.2010.
12. Hawkes R, Leclerc N. Purkinje cell axon collateral distributions reflect the chemical compartmentation of the rat cerebellar cortex. Brain Res. 1989; 476: 279-90.

13. Orduz D, Llano I. Recurrent axon collaterals underlie facilitating synapses between cerebellar Purkinje cells. Proc Natl Acad Sci U S A. 2007; 104: 17831-6. https://doi. org/10.1073/pnas.0707489104.

14. Palkovits M, Mezey E, Hamori J, Szentagothai J. Quantitative histological analysis of the cerebellar nuclei in the cat. I. Numerical data on cells and on synapses. Exp Brain Res. 1977; 28: 189-209.

15. Sugihara I, Fujita H, Na J, Quy PN, Li BY, Ikeda D. Projection of reconstructed single Purkinje cell axons in relation to the cortical and nuclear aldolase $\mathrm{C}$ compartments of the rat cerebellum. J Comp Neurol. 2009; 512: 282-304. https://doi.org/10.1002/cne.21889.

16. Takahashi-Iwanaga $H$. Reticular endings of Purkinje cell axons in the rat cerebellar nuclei: scanning electron microscopic observation of the pericellular plexus of Cajal. Arch Histol Cytol. 1992; 55: 307-14.

17. Uusisaari M, Knopfel T. GABAergic synaptic communication in the GABAergic and non-GABAergic cells in the deep cerebellar nuclei. Neuroscience. 2008; 156: 537-49. https://doi.org/10.1016/j.neuroscience.2008.07.060.

18. Uusisaari M, De Schutter E. The mysterious microcircuitry of the cerebellar nuclei. J Physiol. 2011; 589: 3441-57. https://doi.org/10.1113/jphysiol.2010.201582.

19. Uusisaari M, Knopfel T. Functional classification of neurons in the mouse lateral cerebellar nuclei. Cerebellum. 2011; 10: 637-46. https://doi.org/10.1007/s12311-010-0240-3.

20. Watt AJ, Cuntz H, Mori M, Nusser Z, Sjostrom PJ, Hausser M. Traveling waves in developing cerebellar cortex mediated by asymmetrical Purkinje cell connectivity. Nat Neurosci. 2009; 12: 463-73. https://doi.org/10.1038/ nn. 2285 .

21. Wang DJ, Yang D, Su LD, Xie YJ, Zhou L, Sun CL, Wang Y, Wang XX, Shen Y. Cytosolic phospholipase A2 alpha/arachidonic acid signaling mediates depolarizationinduced suppression of excitation in the cerebellum. PLoS One. 2012; 7: e41499. https://doi.org/10.1371/journal. pone. 0041499 .

22. Wylie DR, De Zeeuw CI, DiGiorgi PL, Simpson JI. Projections of individual Purkinje cells of identified zones in the ventral nodulus to the vestibular and cerebellar nuclei in the rabbit. J Comp Neurol. 1994; 349: 448-63. https://doi. org/10.1002/cne.903490309.

23. Yang Z, Wang JH. Frequency-dependent reliability of spike propagation is function of axonal voltage-gated sodium channels in cerebellar Purkinje cells. Cerebellum. 2013; 12: 862-9. https://doi.org/10.1007/s12311-013-0499-2.

24. Debanne D, Campanac E, Bialowas A, Carlier E, Alcaraz G. Axon physiology. Physiol Rev. 2011; 91: 555-602. https:// doi.org/10.1152/physrev.00048.2009. 
25. Khaliq ZM, Raman IM. Axonal propagation of simple and complex spikes in cerebellar Purkinje neurons. J Neurosci. 2005; 25: 454-63. https://doi.org/10.1523/ JNEUROSCI.3045-04.2005.

26. Monsivais P, Clark BA, Roth A, Hausser M. Determinants of action potential propagation in cerebellar Purkinje cell axons. J Neurosci. 2005; 25: 464-72. https://doi. org/10.1523/JNEUROSCI.3871-04.2005.

27. Yang Z, Gu E, Lu X, Wang JH. Essential role of axonal VGSC inactivation in time-dependent deceleration and unreliability of spike propagation at cerebellar Purkinje cells. Mol Brain. 2014; 7: 1. https://doi. org/10.1186/1756-6606-7-1.

28. Chen N, Chen X, Yu J, Wang JH. After-hyperpolarization improves spike programming through lowering threshold potentials and refractory periods mediated by voltage-gated sodium channels. Biochem Biophys Res Commun. 2006; 346: 938-45.

29. Ge R, Qian H, Wang JH. Physiological synaptic signals initiate sequential spikes at soma of cortical pyramidal neurons. Mol Brain. 2011; 4: 19. https://doi. org/10.1186/1756-6606-4-19.

30. Chen N, Zhu Y, Gao X, Guan S, Wang JH. Sodium channelmediated intrinsic mechanisms underlying the differences of spike programming among GABAergic neurons. Biochem Biophys Res Commun. 2006; 346: 281-7.

31. Ge R, Qian H, Chen N, Wang JH. Input-dependent subcellular localization of spike initiation between soma and axon at cortical pyramidal neurons. Mol Brain. 2014; 7: 26. https://doi.org/10.1186/1756-6606-7-26.

32. Lu W, Wen B, Zhang F, Wang JH. Voltage-independent sodium channels emerge for an expression of activityinduced spontaneous spikes in GABAergic neurons. Mol Brain. 2014; 7: 38. https://doi.org/10.1186/1756-6606-7-38.

33. Aldrich RW, Corey DP, Stevens CF. A reinterpretation of mammalian sodium channel gating based on single channel recording. Nature. 1983; 306: 436-41.

34. Goldman L. Stationarity of sodium channel gating kinetics in excised patches from neuroblastoma N1E 115. Biophys J. 1995; 69: 2364-8.

35. Chen N, Chen SL, Wu YL, Wang JH. The refractory periods and threshold potentials of sequential spikes measured by whole-cell recordings. Biochem Biophys Res Commun. 2006; 340: 151-7.

36. Wei J, Zhang M, Zhu Y, Wang JH. Ca2+-calmodulin signalling pathway upregulates GABA synaptic transmission through cytoskeleton-mediated mechanisms. Neuroscience. 2004; 127: 637-47.

37. Hajos N, Mody I. Synaptic communication among hippocampal interneurons: properties of spontaneous IPSCs in morphologically identified cells. J Neurosci. 1997; 17: 8427-42.

38. Davie JT, Clark BA, Hausser M. The origin of the complex spike in cerebellar Purkinje cells. J
Neurosci. 2008; 28: 7599-609. https://doi.org/10.1523/ JNEUROSCI.0559-08.2008.

39. Harvey RJ, Porter R, Rawson JA. The natural discharges of Purkinje cells in paravermal regions of lobules V and VI of the monkey's cerebellum. J Physiol. 1977; 271: 515-36.

40. Llinas R, Sugimori M. Electrophysiological properties of in vitro Purkinje cell somata in mammalian cerebellar slices. J Physiol. 1980; 305: 171-95.

41. Loewenstein Y, Mahon S, Chadderton P, Kitamura K, Sompolinsky H, Yarom Y, Hausser M. Bistability of cerebellar Purkinje cells modulated by sensory stimulation. Nat Neurosci. 2005; 8: 202-11. https://doi.org/10.1038/ nn1393.

42. Shin M, Moghadam SH, Sekirnjak C, Bagnall MW, Kolkman KE, Jacobs R, Faulstich M, du Lac S. Multiple types of cerebellar target neurons and their circuitry in the vestibulo-ocular reflex. J Neurosci. 2011; 31: 10776-86. https://doi.org/10.1523/JNEUROSCI.0768-11.2011.

43. Zhang W, Linden D. The other side of the engram: experience-driven changes in neuronal intrinsic excitability. Nat Rev Neurosci. 2003; 4: 885-900.

44. Eccles JC, Sasaki K, Strata P. Interpretation of the potential fields generated in the cerebellar cortex by a mossy fibre volley. Exp Brain Res. 1967; 3: 58-80.

45. Bliss TV, Collingridge GL. A synaptic model of memory: LTP in the hippocampus. Nature. 1993; 361: 31-9.

46. Chen N, Chen X, Wang JH. Homeostasis established by coordination of subcellular compartment plasticity improves spike encoding. J Cell Sci. 2008; 121: 2961-71.

47. Debanne D, Poo MM. Spike-timing dependent plasticity beyond synapse - pre- and post-synaptic plasticity of intrinsic neuronal excitability. Front Synaptic Neurosci. 2010; 2: 21. https://doi.org/10.3389/fnsyn.2010.00021.

48. Daoudal D, Debanne D. Long-term plasticity of intrinsic excitability: learning rules and mechanisms. Learn Mem. 2003; 10: 456-65.

49. Linden DJ. The return of the spike: postsynaptic action potentials and the induction of LTP and LTD. Neuron. 1999; 22: 661-6. https://doi.org/10.1016/S0896-6273(00)80726-6.

50. Turrigiano GG, Nelson SB. Hebb and homeostasis in neuronal plasticity. Curr Opin Neurobiol. 2000; 10: 358-64.

51. Wang D, Zhao J, Gao Z, Chen N, Wen B, Lu W, Lei Z, Chen C, Liu Y, Feng J, Wang JH. Neurons in the barrel cortex turn into processing whisker and odor signals: a cellular mechanism for the storage and retrieval of associative signals. Front Cell Neurosci. 2015; 9: 1-12. https://doi. org/10.3389/fncel.2015.00320.

52. Chen N, Yu J, Qian H, Ge R, Wang JH. Axons amplify somatic incomplete spikes into uniform amplitudes in mouse cortical pyramidal neurons. PLoS One. 2010; 5: e11868.

53. Yang F, Cui Y, Wang K, Zheng J. Thermosensitive TRP channel pore turret is part of the temperature activation 
pathway. Proc Natl Acad Sci U S A. 2010; 107: 7083-8. https://doi.org/10.1073/pnas.1000357107.

54. Yu J, Qian H, Wang JH. Upregulation of transmitter release probability improves a conversion of synaptic analogue signals into neuronal digital spikes. Mol Brain. 2012; 5: 26. https://doi.org/10.1186/1756-6606-5-26.

55. Hockberger PE, Tseng HY, Connor JA. Development of rat cerebellar Purkinje cells: electrophysiological properties following acute isolation and in long-term culture. J Neurosci. 1989; 9: 2258-71.

56. McKay BE, Turner RW. Physiological and morphological development of the rat cerebellar Purkinje cell. J Physiol. 2005; 567: 829-50.

57. Palmer LM, Clark BA, Grundemann J, Roth A, Stuart GJ, Hausser M. Initiation of simple and complex spikes in cerebellar Purkinje cells. J Physiol. 2010; 588: 1709-17. https://doi.org/10.1113/jphysiol.2010.188300.

58. Stuart G, Hausser M. Initiation and spread of sodium action potentials in cerebellar Purkinje cells. Neuron. 1994; 13: 703-12. https://doi.org/10.1016/0896-6273(94)90037-X.

59. Uusisaari M, Obata K, Knopfel T. Morphological and electrophysiological properties of GABAergic and non-GABAergic cells in the deep cerebellar nuclei. J Neurophysiol. 2007; 97: 901-11. https://doi.org/10.1152/ jn.00974.2006.

60. Aizenman CD, Huang EJ, Linden DJ. Morphological correlates of intrinsic electrical excitability in neurons of the deep cerebellar nuclei. J Neurophysiol. 2003; 89: 173847. https://doi.org/10.1152/jn.01043.2002.

61. Freund TF, Buzsaki G. Interneurons of the hippocampus. Hippocampus. 1996; 6: 347-470.

62. Ni H, Huang L, Chen N, Zhang F, Liu D, Ge M, Guan $\mathrm{S}$, Zhu Y, Wang JH. Upregulation of barrel GABAergic neurons is associated with cross-modal plasticity in olfactory deficit. PLoS One. 2010; 5: e13736. https://doi. org/10.1371/journal.pone.0013736.

63. Somogyi P, Klausberger T. Defined types of cortical interneurone structure space and spike timing in the hippocampus. J Physiol. 2005; 562: 9-29.

64. Yu J, Qian H, Chen N, Wang JH. Quantal glutamate release is essential for reliable neuronal encodings in cerebral networks. PLoS One. 2011; 6: e25219.

65. Wang JH, Kelly PT. Ca2+/CaM signalling pathway up-regulates glutamatergic synaptic function in nonpyramidal fast-spiking neurons of hippocampal CA1. J Physiol. 2001; 533: 407-22.

66. Yan F, Gao Z, Chen P, Huang L, Wang D, Chen N, Wu R, Feng J, Cui S, Lu W, Wang JH. Coordinated plasticity between barrel cortical glutamatergic and GABAergic neurons during associative memory. Neural Plast. 2016; 2016: 1-20. https://doi.org/10.1155/2016/5648390.

67. Ma K, Xu A, Cui S, Sun M, Xue Y, Wang JH. Impaired GABA synthesis, uptake and release are associated with depression-like behaviors induced by chronic mild stress.
Transl Psychiatry. 2016; 6: 1-10. https://doi.org/10.1038/ tp.2016.181.

68. Xu A, Cui $\mathrm{S}$, Wang J. Incoordination among subcellular compartments is associated to depressionlike behavior induced by chronic mild stress. Int J Neuropsychopharmacol. 2016; 19: pyv122. https://doi. org/10.1093/ijnp/pyv122.

69. Zhang F, Liu B, Lei Z, Wang J. mGluR1, 5 activation improves network asynchrony and GABAergic synapse attenuation in the amygdala: implication for anxiety-like behavior in DBA/2 mice. Mol Brain. 2012; 5: 20. https:// doi.org/10.1186/1756-6606-5-20.

70. Zhang G, Gao Z, Guan S, Zhu Y, Wang JH. Upregulation of excitatory neurons and downregulation of inhibitory neurons in barrel cortex are associated with loss of whisker inputs. Mol Brain. 2013; 6: 2. https://doi. org/10.1186/1756-6606-6-2.

71. Guo R, Ge R, Zhao S, Liu Y, Zhao X, Huang L, Guan S, Lu W, Cui S, Wang S, Wang JH. Associative memory extinction is accompanied by decayed plasticity at motor cortical neurons and persistent plasticity at sensory cortical neurons. Front Cell Neurosci. 2017; 11: 1-12. https://doi. org/10.3389/fncel.2017.00168.

72. Wang JH, Stelzer A. Shared calcium signaling pathways in the induction of long-term potentiation and synaptic disinhibition in CA1 pyramidal cell dendrites. J Neurophysiol. 1996; 75: 1687-702.

73. Hamori J, Szentagothai J. The Purkinje cell baskets: ultrastructure of an inhibitory synapse. Acta Biol Acad Sci Hung. 1965; 15: 465-79.

74. Gao Z, Chen L, Fan R, Lu W, Wang D, Cui S, Huang L, Zhao S, Guan S, Zhu Y, Wang JH. Associations of unilateral whisker and olfactory signals induce synapse formation and memory cell recruitment in bilateral barrel cortices: cellular mechanism for unilateral training toward bilateral memory. Front Cell Neurosci. 2016; 10: 1-16. https://doi. org/10.3389/fncel.2016.00285.

75. Lu W, Feng J, Wen B, Wang K, Wang JH. Activity-induced spontaneous spikes in GABAergic neurons suppress seizure discharges: an implication of computational modeling. Oncotarget. 2017; 8: 32384-97. https://doi.org/10.18632/ oncotarget. 15660 .

76. Zhu Z, Wang G, Ma K, Cui S, Wang JH. GABAergic neurons in nucleus accumbens are correlated to resilience and vulnerability to chronic stress for major depression. Oncotarget. 2017; 8: 35933-45. https://doi.org/10.18632/ oncotarget.16411.

77. Destexhe A, Mainen ZF, Sejnowski TJ. Kinetic Methods of Synaptic Transmission. (Cambridge and London: MIT Press, 1998).

78. Hasselmo ME, Kapur A. Modeling of Large Networks. (Boca Raton, London, New York and Washington DC: CRC Press, 2001). 